\title{
Uncovering Knowledge Management Practices In Organizations
}

\author{
Visvanathan Naicker, University of South Africa, South Africa
}

\begin{abstract}
Background: An increasing number of organizations have accepted the importance of managing their company's knowledge in a more structured manner. There have been many knowledge management projects that have been introduced, some which have been successful, but many have failed as well. Knowledge management can be introduced in the culture of the company, which then becomes paramount when the company deals with national and international markets.
\end{abstract}

Objectives: There are concerns as to how to measure the benefits of a Knowledge Management (KM) strategy and its concomitant initiatives on the performance of the company. This paper discusses findings from an empirical investigation amongst 51 organizations.

Methods: A mixed methods approach was used to capture the data using many previously validated questionnaires. The questionnaire was adapted to suite the requirements of this particular study.

Results: The findings suggest that by providing effectual information systems infrastructure knowledge can be captured, transformed and disseminated to organizations. Investment in business information systems supports knowledge sharing and interpersonal interaction and therefore facilitates knowledge management processes and strategies.

Conclusion: The importance of this contribution is that it offers suggestions to design a KM approach by means of a new framework emanating from the findings. Finally, contributing to the theoretical analysis and findings from the empirical investigation, this article concludes with suggestions that may assist organizations to address their KM barriers.

Keywords: Knowledge Management; Knowledge Management Culture; Organizational Learning; Knowledge Management Strategy; Knowledge Management Status; Knowledge Management Problems

\section{INTRODUCTION}

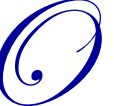

rganizations are now aware of the competitive advantage in transforming their employees' tacit knowledge into organised explicit knowledge (Soley \& Pandya 2003). Technological tools such as applications based on KM databases, the Internet and groupware technologies are readily available to support the increasing use of KM processes. It is increasingly accepted that knowledge is looked upon as the most important resource within a company (Lopes et al. 2005). Hence, many organizations are starting to invest in technological innovations. The research problem that this study addresses is that KM means different things to management within different industries. Organizations are now becoming more responsive for better business processes to effectively address their clients' demands and changes in the market place. It is suggested by Nonaka (1995) that Japanese firms are successful in their efforts towards KM because it has played a significant role in promoting their innovations. The Japanese firms are able to create new knowledge and use it to produce successful products and technologies (Nonaka 1995). The problem for most organizations is that the implementation of KM initiatives has often been unplanned without a strategy for performance measurement (Griffiths and Remenyi 2008). Zhu (2004) professes that KM is a loose set of ideas, practices and tools centering the creation, communication and utilisation of the organizations' knowledge. Furthermore, Zhu (2004) states that KM is becoming the most universal 
management concept across organizations. Many of the new business models that are emerging in the global economy have its core in the basic activity of the modern value chain namely: knowledge management. Therefore, during recent times, terms like digital economy, information society and knowledge society have escalated as areas of interest and research in academic and company settings (Evangelista et al. 2010). This article is based on research in the area of KM strategies and practices in South Africa. The organizations that were researched came from diverse business sectors incorporating large and small enterprises. The idea behind this research was to understand how employees view technology and KM within their organizations. The research addressed by this study is as follows. Firstly, how do employees respond with regard to KM and its principles? Secondly, what role does KM play in the creation of knowledge based organizations? Thirdly, do firms gain a strategic advantage through the use of KM? Finally, the last objective of this study was to establish the level of importance managers give to the concept of KM within their firms.

In the following section, the literature review with its sub-sections are presented, the research model is presented and its theoretical foundation. The research methodology is discussed, followed by a discussion of the empirical results and the implications. Finally, the conclusion, a summary of the key findings and suggestions for future research are presented.

\section{KNOWLEDGE MANAGEMENT PROBLEMS}

As recognised by Iftikhar (2003) knowledge is an expensive commodity, which if managed properly becomes an advantage to the company. Moreover, an important caveat noted by Iftikhar is that the fiercest struggle in the workplace of the future may be for the hearts and minds of employees in addition to that of its clients. Iftikhar (2003) states that organizations invest in their knowledge assets by recruiting educated people and then training them. By securing a knowledgeable workforce, the company can gain a competitive advantage by retaining and managing the in-house knowledge (Gray 2001 \& Neve 2003). Scholars have argued that knowledge including factors such as intuition, wisdom, experience and social networking is hard to gain but can be easily lost (Coakes 2000; Vakola 2000; Iftikhar 2003). Knowledge Management is a topic that has been getting much attention from consultancy firms as well as the academic realm in that Wilson (2002) argues that most renowned academic institutions have shied away from the topic based on the fact that knowledge (i.e. what a person knows) cannot be managed (which is in direct conflict to what this paper is suggesting) and only information can be managed. According to (Trigg 2000; Neumann \& Tome 2011) the transition of KM has become more evident. In addition, the world's financial markets are struggling with the concept that knowledge represents a greater competitive advantage than traditional resources such as equipment, capital and labour (Trigg 2000).

\section{Knowledge Management Status}

Horwitch and Amacost (2002) describes KM as the creation extraction, transformation and storage of the correct knowledge in order to design better policy, modify action and deliver results. During the past decade, there has been an explosive growth in research on KM in many organizations. According to Kruger and Johnson (2008), KM is fairly institutionalised in South African organizations and their findings indicated that there was a significant growth in KM, which occurred during the past five years. Cater and Scarbrough (2001) and Peltoniemi (2007) advocate that $\mathrm{KM}$ is an attempt by management to actively create, communicate and exploit knowledge as a resource for the company. Research by Ferguson, Huysman \& Soekijad (2010) provide further justification for this move, as they perceive KM as organizational practices that facilitate and structure knowledge sharing and learning. Cater and Scarbrough (2001) view KM where it involves centralising knowledge that is currently scattered across the company into a more explicit form where everyone may have access to it in relation to their business need. Hence, there are two pivotal KM strategies: codification where knowledge is carefully codified and stored in databases, and access that could be achieved by all within the company (McElroy 2000).

\section{Knowledge Management Culture}

According to (Kahal 1994; Soley \& Pandya 2003) if international business dealings are ignorant of cultural differences, then it is not only unfortunate but also bad for business. Based on (Kahal 1994; Soley \& Pandya 2003) views, questions should be raised as to how much knowledge organizations possess regarding culture. The general 
pattern seems to be a lack of understanding and knowledge sharing, thus bringing culture under the spotlight. KM includes the way that organizations function, communicate, analyse situations, come up with new ideas and develop new ways of doing business (Carrillo et al. 2003). Moreover, due to the diversity in management structures, KM can also involve issues of culture, values and skills. As suggested by previous studies a supportive culture is essential for the successful implementation of KM initiatives (Soley \& Pandya 2003). Organizations have realised that in order to foster a supportive KM culture for their staff, drivers of KM projects must be able to appreciate and recognise the value of KM initiatives (Soley \&Pandya 2003).

\section{Knowledge Management Strategy}

Company knowledge is a mixture of explicit and tacit knowledge and the role of $\mathrm{KM}$ is to influence the different types of knowledge so that it improves business processes becomes available as a company asset (Davenport et al. 1998; Lopez et al. 2004). From a strategic business point of view, Wong (2000) avers that the resource based strategy paradigm emphasises distinctive company specific and thus hard to imitate assets, skills and knowledge. Furthermore, proponents of resource-based theory suggest that knowledge-based advantages are difficult to imitate when the reasons for superior performance cannot be identified or controlled (Dierick \& Cool 1989; Lippman \& Rumelt 1982). Wu \& Lin (2009) argue that knowledge resources are not only unique but could also provide a valuable link to a competitive advantage to a business, if it is efficiently and effectively utilised. They say that the fundamental determinant of how KM is effectively executed is through the organizations' competitive strategy. Gyensare \& Asare (2012) state that when organizations explore and strategically manage their intangible assets efficiently and effectively - it may be referred to as Knowledge Management. This research was conducted to investigate what practices South African organizations were using to ensure effective knowledge transfer within their organizations. The objectives of this study were:

- $\quad$ To investigate and discuss the status culture KM problems of contemporary business practices.

- $\quad$ KM strategies and whether technology can overcome KM problems found in South African organizations.

- The purpose is to identify the foundation that supports KM within South African organizations.

It is within this framework and based on a quantitative approach that the South African scenario on KM is presented.

\section{GENERAL HYPOTHESIS}

Certain cultural, technological, strategy and company problems could effect South African organizations in local and international markets and if it is not taken seriously, could result in misunderstandings that may result in lost time, money and further business collaboration.

\section{RESEARCH FRAMEWORK}

According to Khalifa and Liu (2003), state that the application of institutional theory and infrastructural capabilities are the main constructs which aligns culture, strategy and behavious with KM goals. Therefore, the researcher hypothesised that KM objectives should be derived from KM technology capabilities. In addition to KM culture, problems, strategies and the company's status of KM, common benchmarks of KM success includes innovativeness, coordination, time-to-market, adaptability and responsiveness to changes (Gold et al. 2001). The research framework (see Figure 1) applies the theory of technology capabilities in explaining KM success. These structures take the form of company norms, culture, strategy and corporate policies. Khalifa and Liu (2003), state that an information technology capability by itself is insufficient for improved company performances. Instead, they argue that IT capabilities are completely mediated through the KM process. Findings from the Gold et al (2001), study indicated knowledge infrastructural and process capabilities had direct and independent implications over company effectiveness. A shortcoming in their study did not account for the interrelationships between the KM structure and KM processes within the company. It is therefore stipulated that Information Technology (technical) capabilities directly affect the success of KM. More specifically, it is hypothesised that KM status, KM culture, KM problems and KM strategy has a significant positive effect on KM technical capabilities. 


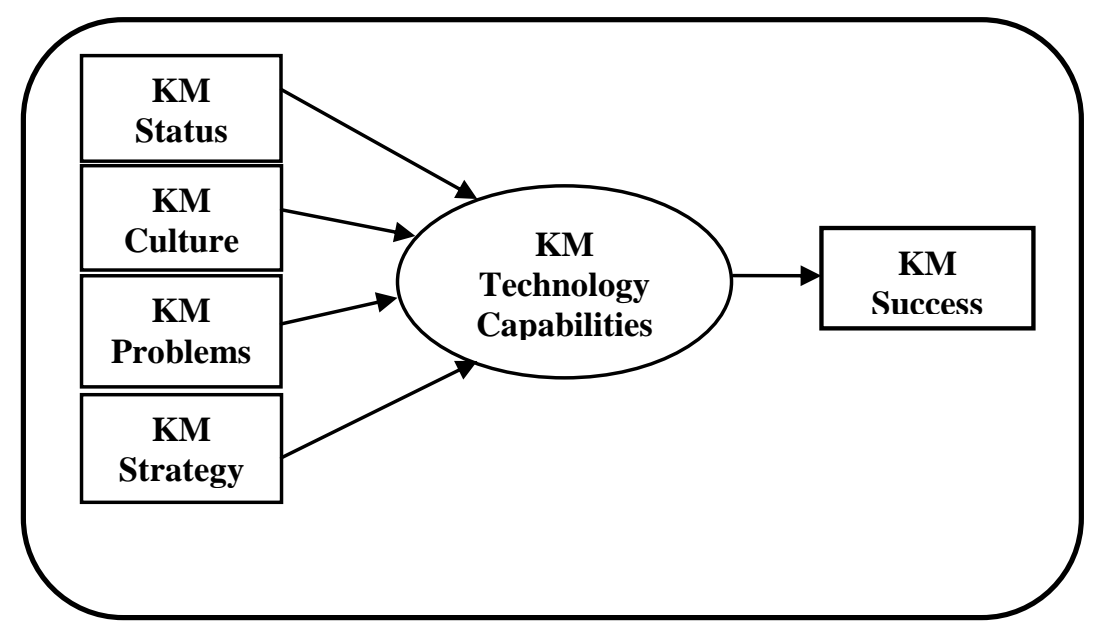

Figure 1: Research Framework

\section{METHODOLOGY}

A random sample of 100 organizations in the Western Cape business district was selected to participate in this study. The participants targeted in the respective businesses to complete the questionnaire were the Chief Information Officers, IT managers. The questionnaire was derived from well-validated portions of several surveys, literature reviews and present 'real-life' experiences that have been used recently. The respondents were requested to complete the questionnaire individually. The questionnaire contained 20 questions consisting of short questions, multiple choices, open-ended, dichotomous as well as opinion type questions. Fifty-one usable responses were received which provided a response rate of $51 \%$. The questionnaire tapped into the respondents' perceptions of KM cultures, KM problems, KM strategies and technological issues, which could overcome the KM issues found in South African businesses.

\section{FINDINGS}

\section{Demographics}

The profile of the sample was observed in terms of the respondents' occupation, experience with KM, the importance of KM in relation to their daily working patterns, and their role in KM activities. Respondents who have completed the questionnaire can be described as being working within a firm with a minimum of 5 years of experience in KM. The data was first captured onto an excel spreadsheet as excel enables ease of capture. After some typographical errors were discovered, a second entry (double entry) was necessary to ensure that the data was correctly captured. Once this procedure was completed and the data verified to be correct, it was imported into SAS v9 for further analysis. Because the questionnaire contained both ordinal and nominal data, it was somewhat challenging to use all the responses to the questionnaire to address the aims and objectives of the study. A summary of the responses to each of certain questions (namely question 1 and 2; question 4 to question 12 and question 16) are undertaken. For example, (see Table 1) for question 1, there were $23 / 49=46.94 \%$ who answered with a ' 4 ' (Growth Stage).

Table 1: Frequencies for Status

\begin{tabular}{|l|c|c|c|c|}
\hline Q1 & Frequency & Percent & Cumulative Frequency & Cumulative Percent \\
\hline 1 & 7 & 14.29 & 7 & 14.29 \\
\hline 2 & 6 & 12.24 & 13 & 26.53 \\
\hline 3 & 13 & 26.53 & 26 & 53.06 \\
\hline $\mathbf{4}$ & $\mathbf{2 3}$ & $\mathbf{4 6 . 9 4}$ & 49 & 100.00 \\
\hline
\end{tabular}

More interesting questions are those where respondents could 'tick all that apply', such as Question 3 (i.e. What are the problems regarding knowledge management in your company?) where there are 6 parts. The analysis 
conducted was done using generalised linear models to account for the dependency among responses by the same subject. Specifically, the Genmod procedure in SAS v9 was used for the analysis. Since there were many pairwise comparisons to be made, an adjustment for multiple testing was used. The Tukey-Kramer adjustment was used. Pairs of options were deemed to have significantly different proportions of responses when the adjusted p-value is less than 0.05. The reasoning behind this was that one could see cases that might be 'close' to significant; the output contains pairs with p-values $<0.10$. From the output for question 3 below part 5 (i.e. Poor sharing of knowledge in the organization) was selected most often (40.8\% of the time) while part 1 (Lack of Information) was selected least often (only $4.1 \%$ of the time). However, the only pairs with adjusted p-values less than 0.05 are parts 1 and 5 and parts 1 and 4 . Parts 1 and 2 were close to meeting the significance level with adjp $=0.0542$. This means that even though (to the naked eye) the response rate for part $5(40.8 \%)$ and part $3(18.4 \%)$ might 'appear' to be different, based on the sample size the difference is not significant at the 0.05 (adjusted) level.

Table 2: Ranking of 6 Parts of Question 3

\begin{tabular}{|l|c|l|}
\hline Obs & Part & Percent \\
\hline $\mathbf{1}$ & $\mathbf{5}$ & $\mathbf{0 . 4 0 8 1 6}$ \\
\hline 2 & 4 & 0.36735 \\
\hline 3 & 2 & 0.26531 \\
\hline 4 & 6 & 0.22449 \\
\hline 5 & 3 & 0.18367 \\
\hline $\mathbf{6}$ & $\mathbf{1}$ & $\mathbf{0 . 0 4 0 8 2}$ \\
\hline
\end{tabular}

Table 3: Ranking of 6 Parts of Question 3 - The Genmod Procedure

\begin{tabular}{|c|c|c|c|}
\hline Source & DF & Chi- Square & Pr > ChiSq \\
\hline Part & 5 & 24.27 & 0.0002 \\
\hline
\end{tabular}

Score Statistics for Type 3 GEE Analysis

Table 4: Significant Differences between Parts for Question 3

\begin{tabular}{|l|c|c|c|c|c|c|c|c|c|c|}
\hline Obs & No & Effect & Part & Part & Estimate & StdErr & zValue & Probz & Adjmnt & Adjp \\
\hline 1 & 1 & part & 1 & 2 & 2.1384 & 0.7581 & 2.82 & 0.0048 & Tukey-Kramer & 0.0542 \\
\hline 3 & 1 & part & $\mathbf{1}$ & $\mathbf{4}$ & 2.6134 & 0.7647 & 3.42 & 0.0006 & Tukey-Kramer & $\mathbf{0 . 0 0 8 3}$ \\
\hline 4 & 1 & part & $\mathbf{1}$ & $\mathbf{5}$ & 2.7854 & 0.7678 & 3.63 & 0.0003 & Tukey-Kramer & $\mathbf{0 . 0 0 3 9}$ \\
\hline
\end{tabular}

Similarly, for question 13 (i.e. which of the following technologies have your company implemented?), part 1 was selected most often $(91.8 \%)$ and part 11 least often (4.1\%). However, parts 1 and 3 are not significantly different. Part 11 differs significantly from 1,3,2, and 8 but not the other parts.

Table 5: Ranking of 11 Parts of Question 13

\begin{tabular}{|l|c|l|}
\hline \multicolumn{1}{|c|}{ Obs } & Part & Percent \\
\hline 1 & $\mathbf{1}$ & $\mathbf{0 . 9 1 8 3 7}$ \\
\hline 2 & 3 & 0.69388 \\
\hline 3 & 2 & 0.61224 \\
\hline 4 & 8 & 0.61224 \\
\hline 5 & 4 & 0.36735 \\
\hline 6 & 9 & 0.36735 \\
\hline 7 & 6 & 0.28571 \\
\hline 8 & 5 & 0.24490 \\
\hline 9 & 7 & 0.16327 \\
\hline 10 & 10 & 0.16327 \\
\hline 11 & $\mathbf{1 1}$ & $\mathbf{0 . 0 4 0 8 2}$ \\
\hline
\end{tabular}

Table 6: Ranking of 11 Parts of Question 13 - The Genmod Procedure

\begin{tabular}{|c|c|c|c|}
\hline Source & DF & Chi- Square & Pr > ChiSq \\
\hline Part & 10 & 42.69 & $<.0001$ \\
\hline
\end{tabular}

Score Statistics for Type 3 GEE Analysis 
Table 7: Significant Differences between Parts for Question 13

\begin{tabular}{|c|c|c|c|c|c|c|c|c|c|c|}
\hline Obs & No & Effect & Part & Part & Estimate & StdErr & zValue & Probz & Adjustment & Adjp \\
\hline 1 & 1 & part & 1 & 2 & -1.9636 & 0.4935 & -3.98 & $<.0001$ & Tukey-Kramer & 0.0034 \\
\hline 3 & 1 & part & 1 & 4 & -2.9640 & 0.5810 & -5.10 & $<.0001$ & Tukey-Kramer & $<.0001$ \\
\hline 4 & 1 & part & 1 & 5 & -3.5464 & 0.5690 & -6.23 & $<.0001$ & Tukey-Kramer & $<.0001$ \\
\hline 5 & 1 & part & 1 & 6 & -3.3367 & 0.6037 & -5.53 & $<.0001$ & Tukey-Kramer & $<.0001$ \\
\hline 6 & 1 & part & 1 & 7 & -4.0545 & 0.6070 & -6.68 & $<.0001$ & Tukey-Kramer & $<.0001$ \\
\hline 7 & 1 & part & 1 & 8 & 1.9636 & 0.4935 & -3.98 & $<.0001$ & Tukey-Kramer & 0.0034 \\
\hline 8 & 1 & part & 1 & 9 & -2.9640 & 0.5383 & -5.51 & $<.0001$ & Tukey-Kramer & $<.0001$ \\
\hline 9 & 1 & part & 1 & 10 & -4.0545 & 0.6070 & -6.68 & $<.0001$ & Tukey-Kramer & $<.0001$ \\
\hline 10 & 1 & part & 1 & 11 & -5.5774 & 1.0154 & -5.49 & $<.0001$ & Tukey-Kramer & $<.0001$ \\
\hline 13 & 1 & part & 2 & 5 & -1.5828 & 0.3564 & -4.44 & $<.0001$ & Tukey-Kramer & 0.0005 \\
\hline 14 & 1 & part & 2 & 6 & -1.3730 & 0.3798 & -3.62 & 0.0003 & Tukey-Kramer & 0.0134 \\
\hline 15 & 1 & part & 2 & 7 & -2.0909 & 0.4824 & -4.33 & $<.0001$ & Tukey-Kramer & 0.0007 \\
\hline 18 & 1 & part & 2 & 10 & -2.0909 & 0.4550 & -4.60 & $<.0001$ & Tukey-Kramer & 0.0002 \\
\hline 19 & 1 & part & 2 & 11 & -3.6138 & 0.8467 & -4.27 & $<.0001$ & Tukey-Kramer & 0.0010 \\
\hline 20 & 1 & part & 3 & 4 & -1.3619 & 0.4187 & -3.25 & 0.0011 & Tukey-Kramer & 0.0450 \\
\hline 21 & 1 & part & 3 & 5 & -1.9443 & 0.3870 & -5.02 & $<.0001$ & Tukey-Kramer & $<.0001$ \\
\hline 22 & 1 & part & 3 & 6 & -1.7346 & 0.3901 & -4.45 & $<.0001$ & Tukey-Kramer & 0.0005 \\
\hline 23 & 1 & part & 3 & 7 & -2.4524 & 0.4515 & -5.43 & $<.0001$ & Tukey-Kramer & $<.0001$ \\
\hline 25 & 1 & part & 3 & 9 & -1.3619 & 0.3980 & -3.42 & 0.0006 & Tukey-Kramer & 0.0261 \\
\hline 26 & 1 & part & 3 & 10 & -2.4524 & 0.5112 & -4.80 & $<.0001$ & Tukey-Kramer & $<.0001$ \\
\hline 27 & 1 & part & 3 & 11 & -3.9753 & 0.8101 & -4.91 & $<.0001$ & Tukey-Kramer & $<.0001$ \\
\hline 34 & 1 & part & 4 & 11 & -2.6134 & 0.8224 & -3.18 & 0.0015 & Tukey-Kramer & 0.0566 \\
\hline 37 & 1 & part & 5 & 8 & 0.3821 & 0.3821 & 4.14 & $<.0001$ & Tukey-Kramer & 0.0017 \\
\hline 42 & 1 & part & 6 & 8 & 0.3564 & 0.3564 & 3.85 & 0.0001 & Tukey-Kramer & 0.0055 \\
\hline 46 & 1 & part & 7 & 8 & 2.0909 & 0.4259 & 4.91 & $<.0001$ & Tukey-Kramer & $<.0001$ \\
\hline 47 & 1 & part & 7 & 9 & 1.0905 & 0.3615 & 3.02 & 0.0026 & Tukey-Kramer & 0.0898 \\
\hline 50 & 1 & part & 8 & 9 & -1.0004 & 0.3140 & -3.19 & 0.0014 & Tukey-Kramer & 0.0552 \\
\hline 51 & 1 & part & 8 & 10 & -2.0909 & 0.4259 & -4.91 & $<.0001$ & Tukey-Kramer & $<.0001$ \\
\hline 52 & 1 & part & 8 & 11 & -3.6138 & 0.8467 & -4.27 & $<.0001$ & Tukey-Kramer & 0.0010 \\
\hline 54 & 1 & part & 9 & 11 & -2.6134 & 0.8224 & -3.18 & 0.0015 & Tukey-Kramer & 0.0566 \\
\hline
\end{tabular}

As above, tests were conducted to see if there were significant differences in the responses across parts. Generalised linear models for Ordered Multinomial Data were used for analyses. For question 17 (i.e. Please rate the knowledge provided to your company government or industry associations based on a scale of 1-7 where 1 is very poor and 7 is excellent.), there are only three parts. Part 2 has the highest mean score (4.73) while part 3 has the lowest mean (4.31). These two are significantly different (adjusted $\mathrm{p}=0.0078$ ) but neither is significantly different from part 1. For question17, part 8 has the highest mean (6.00) and part 4 has the lowest mean (4.04). Part 8 is significantly different from parts 4,6 , and 9 . Part 4 is significantly different from all other parts except part 9 .

\section{DATA ANALYSIS FOR HYPOTHESIS TESTING}

In order to add some numerical values to the framework, one needs to have a measure of each quantity. For example, for each respondent a person would need to know the value of 'Status', the value of 'Culture', the value of 'Problems', and the value of 'Strategy' as depicted in Figure 1 above. Moreover, one would then need to assign a value to 'KM Technology Capabilities' and determine whether there was KM 'success' or not. Given those values, one might look at the correlation between measures of 'Status', 'Culture', 'Problems', and 'Strategy' and the measure of 'Technology Capabilities'. Also, one might go further and look at a multiple regression analysis with 'Technology Capabilities' as the response variable and the other four variables. In looking for a relationship between the four constructs and the outcome variable (i.e. question 13), it seemed more feasible to measure the variables on a continuous scale or preferably on an ordinal scale. For Technology capabilities, it would not make sense to look at individual responses because there were too many parts to the question relative to the number of respondents. It was found reasonable to count the number of items ticked, assuming that the more that were ticked equated to the higher the level of technology capabilities. 
A similar process was followed for items in question 3 and question 14 i.e. A higher number ticked corresponded to a higher number of problems. Given the limitations described above, the only analysis that seems appropriate was a series of tests looking for a relationship between each of the eight 'predictor' variables and the (ordinal) outcome variable question 13. Three of the predictor variables (questions 1, 3, and 14) may be considered as ordinal and hence the relationship with question 13 can be examined by using Spearman's Rank Correlation. For the remaining categorical predictor variables, relationships were examined using the Kruskal-Wallis test in conjunction with question13. This can be thought of as a non-parametric one-way analysis of variance to compare the mean count on question 13 for each of the nominal categories of the predictor variable. In view of the fact that eight tests were done, a more stringent level of significance of 0.01 was appropriate rather than the usual 0.05 level.

In the findings below are the Spearman correlations between question 13 and the ordinal predictor variables. The correlation with question 1 is 0.37737 ( $\mathrm{p}$-value for testing Rho $=0$ is 0.0075 ). This correlation is significantly different from zero at the 0.01 level. It was only the Status variable that had a significant relationship with the intermediating variable - Technological Capabilities.

\begin{tabular}{|l|c|}
\hline $\begin{array}{l}\text { Spearman Correlation Coefficients, } \mathrm{N}=49 \\
\text { Prob }>|\mathrm{r}| \text { under H0: Rho }=0 \text { [Question 13] }\end{array}$ \\
\hline & $\mathbf{0 . 3 7 7 3 7}$ \\
\hline Question 1 & $\mathbf{0 . 0 0 7 5}$ \\
\hline Status & -0.09132 \\
\hline & 0.5326 \\
\hline Question 3 & \\
\hline Problems-Q3 & \\
\hline Scores on Q13 for each level of response to Question 1 & \\
\hline
\end{tabular}

Table 8: Analysis Variable: Q13 Technological Capabilities

\begin{tabular}{|c|c|c|c|c|c|c|c|}
\hline \multicolumn{8}{|c|}{ The MEANS Procedure } \\
\hline Status & Obs & $\mathbf{N}$ & Mean & Median & Std Dev & Minimum & Maximum \\
\hline 1 & 7 & 7 & 2.7143 & 2.0000 & 0.9512 & 2.0000 & 4.0000 \\
\hline 2 & 6 & 6 & 3.3333 & 2.5000 & 2.5820 & 1.0000 & 7.0000 \\
\hline 3 & 13 & 13 & 4.6154 & 4.0000 & 2.0631 & 1.0000 & 8.0000 \\
\hline 4 & 23 & 23 & 5.2174 & 5.0000 & 2.5218 & 1.0000 & 10.0000 \\
\hline
\end{tabular}

The other two correlations were not significantly different from zero. Since there was a significant relationship for question 1, researchers look at the mean responses on question 13 for each category of question 1. For those 7 responding with question $1=1$, the mean number of items ticked on question 13 was 2.71 . Those ticking categories 2, 3, and 4 had mean values on question 13 of 3.33, 4.62, and 5.22 respectively. The increasing values of the means are consistent with the positive correlation observed.

Table 9: Analysis Variable: Q3 Technological Capabilities

\begin{tabular}{|l|c|c|c|c|c|c|c|}
\hline \multicolumn{1}{|c|}{ Culture-q10 } & Obs & N & Mean & Median & Std Dev & Minimum & Maximum \\
\hline 1 & 10 & 10 & 4.6000 & 4.5000 & 2.3190 & 1.0000 & 8.0000 \\
\hline $\mathbf{2}$ & 19 & 19 & $\mathbf{5 . 2 1 0 5}$ & 5.0000 & 2.2750 & 2.0000 & 10.0000 \\
\hline $\mathbf{3}$ & 10 & 10 & $\mathbf{3 . 6 0 0 0}$ & 2.5000 & 2.9515 & 1.0000 & 10.0000 \\
\hline 4 & 8 & 8 & 3.6250 & 3.5000 & 1.9955 & 1.0000 & 7.0000 \\
\hline 5 & 2 & 2 & 4.5000 & 4.5000 & 0.7071 & 4.0000 & 5.0000 \\
\hline
\end{tabular}

\begin{tabular}{|l|l|c|c|}
\hline \multicolumn{5}{|c|}{ Results of Kruskal-Wallis Test for Question 13 and Question 10 } \\
\hline Obs & Name1 & Label1 & Value1 \\
\hline 3 & P_KW & Pr > Chi-Square & 0.3172 \\
\hline
\end{tabular}

Following that table is the p-value for the Kruskal-Wallis test for comparing the responses. For question 10, the mean responses go from 3.60 for question $10=3$ to 5.21 for question $10=2$. The differences are not significant $(p=0.3172)$. None of the variables are significant at the 0.01 level, although question $12(p=0.0435)$ and question $16(\mathrm{p}=0.0280)$ are 'close'. 


\section{DISCUSSION AND ANALYSIS}

Each leading question in the questionnaire had the option for 'Any further comments' and a section was included for further probing when the data collectors sensed that they could probe deeper without causing any discomfort to the respondents. Respondents acknowledged that they are well acquainted with KM and confirm that it is in a growth stage (objective 1) in their respective organizations. Call centers being intensive knowledge users' organizations respondents affirmed that KM is a strategic part of their business because providing accurate advice to customers is the key asset for their industries, making KM becoming part of their organizations' philosophy and culture. Furthermore, respondents confirmed that it takes time for employees to gain the relevant knowledge for customer service and satisfaction and the biggest issues that their organizations faced was employee turnover, with its consequence o loss of knowledge. A few respondents stated that there was a lack of rewards or recognition for knowledge transfer and technical problems such as KM databases access, technical support, security and ethics and non-user-friendly KM software (objective 5) were one of the main causes for the unsuccessful implementation of KM. The literature states that senior managers argue for the configuring of effective technical infrastructure and architectural requirements (Alavi and Leidner, 1999; Khalifa and Lui, 2003). The findings indicate that organizational values influence the way in which they use KM. This is especially relevant in intensive, knowledgehandling organizations where customer satisfaction is at the function of the employee level. Most of the organizations reported that customer satisfaction, due to tougher competition, has increasingly become the focal point in their business in conjunction with the accuracy of knowledge delivered to them is important for business success.

Some common responses to the question 'what are the problems regarding KM in your company? ' were that it was fundamental to have an understanding of whether the organizations were having problems with KM from a lack of information, information overload, re-inventing the wheel and loss of crucial knowledge due to key employees leaving the company (objective 3). After returning from KM training courses, most of the employees failed to contribute the newly acquired knowledge within their respective jobs (objective 2). Many organizations have implemented strategies to promote KM such as 'retain-attract-develop'. This strategy looks at organizations retaining its current knowledge base through its employees as it recognises that the correct employees are a huge asset to its success. Therefore, their retention is non-negotiable (objective 4).

The findings did not provide support for the three constructs namely 'KM Culture', 'Problems in KM' and 'KM Strategy'. This gap however did lead to the development of a new framework, which may increase the use of KM within South African organizations. The framework, see Figure 2 is explained below.

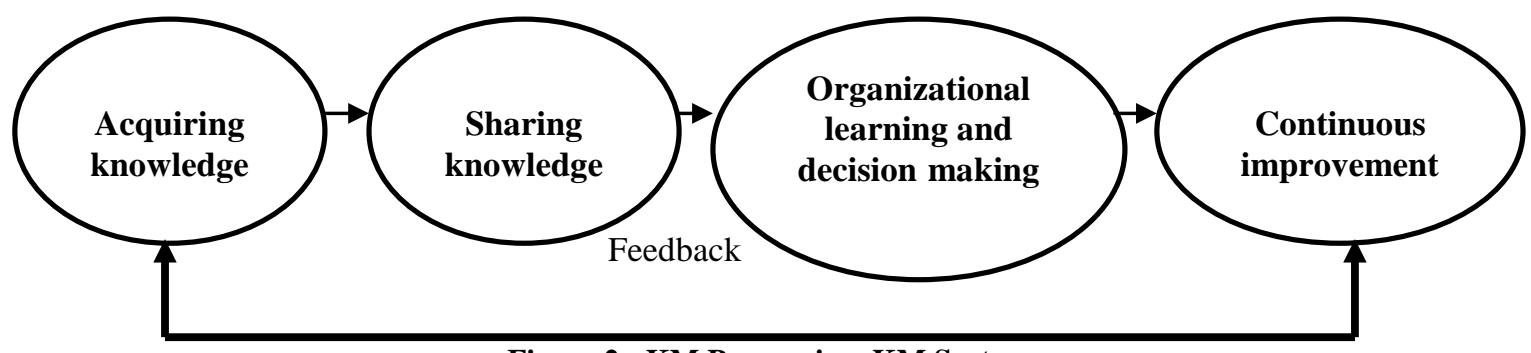

Figure 2: KM Process in a KM System

Acquiring knowledge is the knowledge obtained from resources, which are internal or external to an organization, which may be hired or purchased (Hsieh et al. 2004). Acquiring knowledge has a key success factor for employee involvement an empowerment as the individual will have to involve them in becoming involved to acquire the necessary knowledge needed. Hence, acquiring knowledge has a direct effect on sharing knowledge.

Sharing knowledge comes from the effect of acquiring knowledge. When one acquires knowledge, it would only be helping to the organization as a whole when it is shared. An individual may have plenty of knowledge but if it is not shared then this knowledge does not mean much for the business as it will not be able to be used by other employees. With this in place, it then makes sharing of knowledge much easier. Sharing knowledge has a direct effect on organizational learning. 
Organizational learning and decision-making occur when an organization has made mistakes and failed to reach certain objectives. From these mistakes and failures, learning can take place. If the organization implements the lesson learned to make better decisions going forward, then this is called organizational learning. At this stage the organization has now acquired the knowledge shared the knowledge and now the learning needs to take place in the company. The key success factors relating to this concept are learning cultures, teamwork and senior management leadership and commitment.

Continuous improvement is possible when learning takes place in an organization and the staff members continue to learn. Because of this continuous learning process, constant improvements take place. At the end of this process, after the improvement has been implemented, the organization would have thus learnt from the improvement. Therefore, it makes the process a cyclic and one may postulate that continuous improvement has a direct effect on acquiring knowledge. One can deduce that the framework (see Figure 2) shows us the relationships the four concepts identified in the framework and the process of knowledge in KM systems.

\section{CONCLUSION}

Organizations are making the transition from managing data to management of knowledge. This is inevitable in the digital age in which organizations compete for survival. It is therefore imperative for organizations to stay abreast of the type of knowledge that is lacking in the organization and adapt the KM strategies to optimally service the organizations' purpose. The research aimed at determining what practices organizations were using to ensure effective knowledge transfer within the organization. Four constructs were measured and only the 'Status' of $\mathrm{KM}$ emanated as a significant predictor to Organizational capabilities, which in turn may lead to successful KM in organizations. Evidence suggests that these organizations can justify strong strategic emphasis on KM and a concomitant significant investment of resources in the pursuit of competitive advantage. Technology can only go to a certain point. It can only provide an organization with the reasoning man has built into it. However, it does not have the ability of innovation.

\section{AUTHOR INFORMATION}

Prof Naicker is a Lecturer in the School of Business Leadership at UNISA's Graduate School of Business Leadership. Prior to joining UNISA, he has been lecturing at the University of the Western Cape in the Management department for 6 years after spending 22 years in Information systems in the corporate sector. He was also HOD of the masters and doctoral research within the Management Department in the School of Business and Finance. He is also a reviewer of 5 high impact journals, examiner and supervisor of masters \& doctoral students. Prof Naicker is widely published in Information systems, strategic information systems and has secondary interests in computers and education. E-mail: naickv@unisa.ac.za

\section{REFERENCES}

1. Al-Hawamdeh, S., 2003, Knowledge Management: Cultivating the Knowledge Professionals. Oxford: Chandos Publishing.

2. Alavi, M., 1997, KPMG Peat Marwick U.S.: One Giant Brain, Harvard Business School, Case 9, pp.397108.

3. Alavi, M. \& Leidner, D.E., 1999, Knowledge management systems: Issues, Challenges, and Benefits. Commutations of the Association for information Systems, 1(7), pp.1-37.

4. Baskerville, R. \& Dulipovici, A., 2006, The theoretical foundation of knowledge management. Knowledge management research and practice, (4), pp.83-105.

5. Blackler, F., 1995, Knowledge, knowledge work and organizations: an overview and interpretation. Organizational Studies, 16(6), pp.1021-1047.

6. Carter, C. \& Scarbrough, H., 2001, Towards a second generation of KM. The people management challenge. Education and Training, 43(4), pp.215-224.

7. Carrillo, P.M., Robinson, H.S., Anumba, C.J.\& Al-Ghassani, A.M., 2003, Framework for Linking Knowledge Management to Business Performance. Electronic Journal of Knowledge Management, 1(1), pp.1-12. 
8. Coakes, E., 2000, Graffiti on the Long Wall: A Sociotechnical conversation, The New Sociotech: Graffiti on the Long Wall. by Elayne Coakes, Dianne Willis \& Raymond Lloyd-Jones (Eds.) Springer, London, pp.3-12.

9. Collison, C. \& Parcell, G., 2001, Learning to fly: Practical lessons from one of the world's leading knowledge companies, Capstone, Oxford.

10. Davenport, T.H. \& Prusak, L., 1998, Working knowledge. How s manage what they know. Boston, Massachusetts: Harvard Business School Press.

11. Dierick, I. \& Cool, K., 1989, Asset stock accumulation and sustainability of competitive advantage. Management Sciences, (35), pp.1504-1514.

12. Evangelista, P., Esposito, E., Lauro, V. \& Raffa, M., 2010, The Adoption of Knowledge Management Systems in Small Firms, Electronic Journal of Knowledge Management 8(1), pp.33 - 42.

13. Ferguson, J., Huysman, M. \& Soekijad, M., 2010, Knowledge Management in practice: Pitfalls and potentials for development.

14. Fowler, A. \& Pryke, J., 2003, Knowledge management in public service provision: the child support agency. International Journal of Service Industry Management, 14(3), pp. 254-283.

15. Gray, P.H., 2001, A problem-solving perspective on knowledge management practices, Decision Support Systems, (31), pp. 87-102.

16. Gold, A.H., Malhotra, A. \& Segars, A.H., 2001, Knowledge management: An organizational capabilities perspective, Journal of Management Information Systems, 18(1), pp.185-214.

17. Gopal, C. \& Gagnon, J., 1995, Knowledge Information, Learning and the IS Manager, Computerworld, 1(5), pp. 1-7.

18. Gupta, A. K. \& Govindarajan, V., 2000, Knowledge management's social dimension: Lessons from Nucor Steel, Sloan Management Review, 42(1), pp.71-80.

19. Gumbley, H., 1998, Knowledge Management, Work Study, 47(5), pp.175-177.

20. Griffiths, P. \& Remenyi, D., 2008, Aligning Knowledge Management with Competitive Strategy: A Framework. The Electronic Journal of Knowledge Management, 6(2), pp.125 - 134.

21. Gyensare, M.A. \& Asare, J., 2012, Enhancing innovation and productivity through Knowledge management: The case of unique Trust Bank in Ghana. Journal of Knowledge Management practice, 13(1), pp.1-15.

22. Hansen, M. T., Nohria, N. \& Tierney, T., 1999, What's Your Strategy for Managing Knowledge? Harvard Business Review, 77(2), pp.106-116.

23. Holm, J., 2001, Capturing the spirit of knowledge management, paper presented at the $37^{\text {th }}$ American Conference on Information Systems, Boston, MA, August 3-5.

24. Hsieh, C., Yang, H. \& Lin, B., 2002, Roles of knowledge management in online procurement systems, Industrial Management \& Data Systems, 102(7), pp. 365-70.

25. Horwitch, M. \& Armacost, R., 2002, Helping Knowledge Management be All It Can Be, Journal of Business Strategy, 23(3), pp. 26-31.

26. Iftikhar, Z., 2003, Developing an Instrument for Knowledge Management Project Evaluation, Electronic Journal of Knowledge Management, 1(1), pp.55-62.

27. Kahal, S., 1994, Introduction to International Business. McGraw-Hill, London.

28. Khalifa, M. \& Lui, V., 2003, Determinants of Successful Knowledge Management Programs, Electronic Journal on Knowledge Management, 1(2), pp.103-112.

29. King, W.R., 2003, Invited Viewpoint: The Effective Knowledge Organization, Business Process Management Journal, 9(3).

30. Kruger, C.J.N. \& Johnson, R.D., 2008, Assessment of knowledge management growth: a South Africa perspective. Aslib Proceedings, 61(6), pp.542-564.

31. Laudon,C.K.\& Laudon, P.J., 2012, Management Information Systems: Managing the Digital Firm. $12^{\text {th }}$ edition. Pearson education, Inc, Upper Saddle River, New Jersey, USA.

32. Leedy, P.D. \& Ormrod, J.E., 2004, Practical research: planning and design. $7^{\text {th }}$ edition. Upper Saddle River: Merrill Prentice Hall.

33. Lippman, S. \& Rumelt, R., 1982, Uncertain irritability: An analysis of interfirm differences in efficiency under competitive, Bell Journal of Economics, (13), pp.418-438. 
34. Lopes, I., Martins, M. \& Nunes, M., 2005, Towards the Knowledge Economy: the Technological Innovation and Education Impact on the Value Creation Process The Electronic Journal of Knowledge Management, 3(2), pp. 129-138.

35. Lopez, S.P., Peon-Montes J.M., \& Ordas-Vazquez C.J., 2004, Managing Knowledge: the link between culture and organization learning, Journal of Knowledge Management, 8(6)

36. McElroy,M.W., 2000, Integrating complexity theory, knowledge management and organizational learning, Journal of Knowledge Management, 4(3), pp.195-203.

37. Nonaka, I. \& Takeuchi, H., 1995, Knowledge-Creating Company: How Japanese Organizations Create the Dynamics of Innovation. Oxford University Press.

38. Nonaka, I., 1995, Knowledge-Creating Company: How Japanese Organizations Create the Dynamics of Innovation, Oxford University Press, pp.3-19.

39. Neumann, G. \& Tomé, E., 2011, The Changing Role of Knowledge in Companies: How to Improve Business Performance Through Knowledge, The Electronic Journal of Knowledge Management, 9(1), pp.57-72.

40. Neve, T.O., 2003, Right Questions to Capture Knowledge, Electronic Journal of Knowledge Management, 1(1), pp. 47-54.

41. Orlikowski, W. J., 1992, The duality of technology: Rethinking the concept of Technology in organizations, Organization Science, 3(3), pp. 398-427.

42. Papoutsakis, H. 2007, Sharing Knowledge in the Organization: a Retrospective Analysis and an Empirical Study, The Electronic Journal of Knowledge Management, 5(2), pp. 231 - 244.

43. Peltoniemi, M. 2007, Why do Managers from Different Firms Exchange Information? A Case Study from a Knowledge intensive Industry, The Electronic Journal of Knowledge Management, 5(1), pp. 81 -88.

44. Rowley, J., 2000, Creating learning in higher education, Industrial and Commercial Training, 30(1).

45. Spender, J. C., 1996, Making knowledge the basis of a dynamic theory of the firm, Strategic Management Journal, (17) pp. 45-62.

46. Trigg, J.F., 2000, Knowledge management. Scientific Computing \& Instrumentation.

47. Soley, M. \& Pandya, K.V., 2003, Culture as an Issue in Knowledge Sharing: A Means of Competitive Advantage, Electronic Journal on Knowledge Management, 1(2), pp. 205-212.

48. Vakola, M., 2000, Exploring the relationship between the use of evaluation in business process reengineering and company learning and innovation, The Journal of Management Development, 19(10), pp.812-835.

49. Wenger, E., 2004, Communities of practice: learning, meaning and identity, Cambridge University Press, Cambridge.

50. Wilson, T.D., 2002, The nonsense of Knowledge management, Information Research, 8(1), pp.1-85.

51. Wong, P.K., 2000, Knowledge creation management: Issues and challenges. Strategic Management Journal, (17), pp.193-200.

52. Wu, I.L. \& Lin, H.C., 2009, A strategy based process for implementing knowledge management: An integrative view and empirical study, Journal of the American Society for Information Science and Technology, 60(4), pp.789-802.

53. Zhu, Z., 2004, Knowledge management. Towards a universal concept or cross cultural contexts, Knowledge management Research and Practice Journal, 2(7), pp.67-79. 


\section{NOTES}

